\title{
The future of the pharmaceutical, biological and medical device industry
}

\author{
This article was published in the following Dove Press journal: \\ Open Access Journal of Clinical Trials \\ 6 September 2011 \\ Number of times this article has been viewed
}

\author{
Lesley J Burgess \\ Marli Terblanche \\ TREAD Research/Cardiology Unit, \\ Department of Internal Medicine, \\ Tygerberg Hospital and University \\ of Stellenbosch, Parow, South Africa
}

Correspondence: Marli Terblanche TREAD Research/Cardiology Unit, Department of Internal Medicine, Tygerberg Hospital and Stellenbosch University, Parow, South Africa

Tel +2721 93। 7825

Fax +27 21 9333597

Email marli@treadresearch.com
Abstract: Numerous factors contribute to the declining pharmaceutical industry on the one hand and the rapidly growing generic industry together with the growing importance of medical devices and biologicals on the other. It is clear that the pharmaceutical industry is going to undergo a change in the next decade in order to meet the current challenges facing it and ultimately sustain its profitability and growth. This paper aims to identify a number of fairly obvious trends that are likely to have a significant impact on the product development pipeline in the next decade. It is more than clear that the current production pipeline for pharmaceutical, biotechnology and medical device industries is no longer sustainable and that urgent interventions are required in order to maintain its current level of profitability.

Keywords: pharmaceutical industry, personalized medicine, trends, generics, biotechnology

\section{Introduction}

The withdrawal of high profile drugs (such as Reductil ${ }^{\mathrm{TM}}$ and Vioxx ${ }^{\mathrm{TM}}$ ) from the market following post-marketing studies, the termination of drugs in the late stage of drug development (such as Torcetrapid ${ }^{\mathrm{TM}}$ ), the relative lack of new drugs in the development pipeline, together with the merging of leading pharmaceutical companies, suggest that the pharmaceutical industry is in a crisis.

The BCC Pharmaceutical report maintains that the pharmaceutical industry is one of the most profitable and stable industries. ${ }^{1}$ In 2004, the global pharmaceutical market was estimated to be worth $\$ 554$ billion with a predicted growth rate of $8.2 \%$ per annum. ${ }^{2}$ However, despite this forecast, it is clear that the current product development pipeline has many deficiencies. Due to exorbitant research and development costs, together with falling success rates for new drugs (especially late-stage failures), productivity is decreasing. ${ }^{2-4}$ For instance, during the period 1996-1999, the US Food and Drug Administration (FDA) approved 157 new drugs, while during the period 2006-2009, only 74 drugs were approved. ${ }^{3}$ Of those new drugs making it to the market, only about $30 \%$ will generate sufficient revenue to cover the cost of their research and development. ${ }^{5}$ In addition, the patents on a number of "blockbuster drugs" have expired in the past few years (including those for Lipitor ${ }^{\mathrm{TM}}$, Cozaar ${ }^{\mathrm{TM}}$, Seroquel ${ }^{\mathrm{TM}}$ and Plavix ${ }^{\mathrm{TM}}$ ), resulting in a myriad of mergers and acquisitions within the industry in an attempt to retain profitability. ${ }^{2}$ The situation is further exacerbated by the rapid growth in the generic industry, coupled with increased patient and physician acceptance thereof. ${ }^{2}$ The growing importance of other products, such as medical devices and biologicals, also cannot be ignored. It is clear that the pharmaceutical industry will have to undergo a change in the next decade in order to meet the current challenges 
facing it and ultimately sustain its profitability and growth. In our opinion, there are a number of fairly obvious trends that are likely to have a significant impact on the future product development pipeline in the next decade.

\section{The generics market}

The intense global pressure to reduce healthcare costs, together with the increasing number of drugs reaching the end of their patent, is resulting in increasing competition for pharmaceutical companies by generic manufacturers. In fact, by 2008 , the patents of $80 \%$ of the blockbusters that were marketed in 2000 had terminated, exposing an estimated US\$50-\$70 billion to generic erosion and a projection that global sales for the top 10 selling drugs in 2004 will shrink by $82 \%$ in $2011 .{ }^{6}$ In 2005 , the generics market was worth an estimated $\$ 60$ billion; this is expected to increase significantly in the next few years. Much of this challenge comes from developing countries such as India which do not respect patent protection and are able to develop, test and manufacture generics at a fraction of what it costs in the West. ${ }^{7}$

In addition to these factors, managed health care and other insurance providers are also seeking to reduce and control healthcare costs through generic substitution. ${ }^{8}$

The following is envisaged for the next 10 years:

- Ongoing drive to decrease the cost of health care, in particular prescription drugs.

- Pharmaceutical companies will attempt to prolong patent expiries by various means, for example supplementary protection certificates, life-cycle management, second pharmaceutical use claims and patent settlements and/ or reverse payments. ${ }^{9}$

- The generics market is expected to increase significantly.

- Many of these cheaper generics will continue to come from countries such as India, China and those in Eastern Europe.

\section{Changing demographics}

World-wide, the number of people over the age of 60 has tripled in the last 50 years, and it is expected to triple again in the next $50 .{ }^{10}$ In addition, there will be a female predominance in this age group. This aging population is likely to have a significant impact on the current healthcare system especially with regard to the prevalence of chronic conditions and diseases such as Alzheimer's disease, muscular degeneration, cancer, stroke, chronic obstructive airways disease and cardiovascular disease. For instance, it has been estimated that $80 \%$ of people over the age of 65 years have a chronic condition, while $50 \%$ have two. ${ }^{11}$ So great is this challenge, that the European Forum for Good Clinical Practice (EFGCP) held a workshop in Belgium last year, entitled "The challenge of an aging population for medical research: $1 / 3$ of the EU population will be more than 60 years of age in 50 years' time". ${ }^{12}$

This "silver tsunami" will probably affect medical research and consequent product development in the following ways:

- Clinical research protocols will start catering for this aging population by extending the eligibility of clinical trials to include them. Many current trials, for instance, limit the maximum age for inclusion, exclude any degree of renal impairment, minimize concomitant medications and exclude patients with many of the other chronic conditions associated with aging. By addressing these issues, clinical trial results will have more relevance to the aging population.

- Most phase I studies are conducted in young fit male volunteers with pharmacokinetic and pharmacodynamic profiles which differ greatly from the older, femalepredominant population of the future. In addition, due to the fact that a large percentage of this population is already being treated for one or more chronic conditions, the application of these trial results to the aging population needs to be questioned. On the otherhand, the vulnerability of older patients and their access to medical research benefits complicate their inclusion in clinical trials. Medical researchers and ethicists will need to address this issue.

- There will be a greater drive by the pharmaceutical, biotechnical and medical device industries to research and develop products that can be used to treat chronic conditions typically associated with aging, multi-factorial disorders such as cancer, and lifestyle conditions such as obesity, impotence and balding. Many of these products may not be able to offer a cure, but are likely to slow the rate of development of the disease - such as the current development of a monoclonal antibody by Roche for the progression of Alzheimer's disease. ${ }^{13}$

- In addition, another focus of future product pipelines will be prevention, to ensure that the aging population stays healthy and independent for as long as possible. Although preventative drugs may initially add to the rising price of healthcare, ultimately they could prolong life, improve the quality of life and reduce costs (for example by reducing the need for chronic medication and nursing). 


\section{Globalization}

The globalization of clinical research from predominantly first world countries to poorer, undeveloped ones has been increasing significantly over the past 2 decades. This trend looks set to continue with 24 of the 25 fastest growing countries being from emerging regions. ${ }^{14}$ The basis for this trend is two-fold: firstly, the cost of clinical trials is much lower in these countries and secondly, in many cases, many patients from developed countries are simply not interested in becoming trial participants.

In the next decade, developing countries will also be the target for increased pharmaceutical sales - in particular the E7 countries (China, Indonesia, India, Turkey, Russia, Brazil and Mexico). These countries are not only regarded as being some of the fastest-growing economies in the world, but they also provide new markets with aging populations demanding better and more developed healthcare. With a combined population of approximately 3 billion, PriceWaterhouse Cooper estimates that pharmaceutical sales from these countries could account for $20 \%$ of global sales by $2012 .{ }^{15}$ Much of this growth is attributable to an increase in lifestyle diseases associated with a poor diet and an increasingly sedentary lifestyle, for example diabetes, obesity and hypertension. The prevalence of counterfeit drugs and lack of protection of intellectual property remain a huge challenge in these countries.

Predictions for this sector within the next decade include:

- The increased trend in globalization with regards to clinical trials continues. Stricter regulations come into being to deal with data emanating from these countries.

- An increase in pharmaceutical sales in developing countries, especially the E7 countries, as their economic expansion continues at a faster rate than in the $\mathrm{G} 7$ countries.

- More attention is paid to control the problems pertaining to intellectual property and consequent counterfeit drugs.

- More and more of the pharmaceutical companies and clinical research organizations expand their offices into these countries. In particular, Asian companies start merging and acquiring pharmaceutical companies from developed nations. Developing countries start manufacturing more and more of the world's pharmaceutical products.

- Research and development is focused on the lifestyle diseases and chronic conditions which are becoming predominant in these $\mathrm{E} 7$ countries.

\section{Biotechnology}

According to Fillmore, the biotechnology industry is undoubtedly regarded as the most likely source for innovative products. ${ }^{16}$ For more than a decade now, there has been an increase in the number of approvals of new biologicals and they have constituted an increasingly larger percentage of all drug approvals in the last few years. Much of this growth is related to improved recombinant technologies. Oncology is the most rapidly growing segment, mainly due to the increase in adjunctive therapies and high cost of effective biotherapies. Sales have increased from an estimated $\$ 30$ billion in 2005 to $\$ 65$ billion forecasted for $2010 .{ }^{17}$ One has only to look at the product pipeline of large pharmaceutical companies such as Pfizer and Novartis to realize the extent of this increase and the extent to which oncology drugs are included in this pipeline. ${ }^{18,19}$ According to Burrill, "biotechnology is driving a global transformation from the treatment of illness to the treatment of wellness; at the same time, the changing world is transforming biotechnology". ${ }^{20}$

A number of biologicals either have or will reach the end of their patents within the next 3-5 years, including Humulin $^{\mathrm{TM}}$, Avastatin ${ }^{\mathrm{TM}}$, Remicade ${ }^{\mathrm{TM}}$ and Cerezyme ${ }^{\mathrm{TM}}{ }^{21}$ This has resulted in the research and development of alternative versions of biologic products, referred to as biosimilars. ${ }^{22}$ This is likely to cause a few problems as the characteristics of biologicals are integrally entwined with the manufacturing process. Currently regulations pertaining to the marketing of such agents are unclear.

The changes envisaged in the next decade with regards to this issue are:

- The biotechnology industry will continue to grow and will develop its own expertise with regards to clinical trials.

- The biotechnology industry will expand to countries other than the USA and Europe.

- There will be an increase in partnering agreements between major pharmaceutical companies and biotechnology companies.

- Regulatory and ethical issues with regard to biosimilars will be dealt with.

\section{Personalized medicine and companion diagnostic tests}

In recent years, it has become apparent that the "one-sizefits-all" approach to drug research and development is flawed. The efficacy rate of many drugs is only $25 \%-60 \%{ }^{23}$ Furthermore, adverse drug reactions cost the European Union nearly $€ 79$ billion annually and are listed as the fourth most common cause of death. ${ }^{23-25}$ The development 
of personalized medicine, or "the right drug for the right patient at the right time", offers a potential solution to this problem and is based on the emerging capabilities within the field of pharmacogenomics. Interest in this field has grown significantly over the last decade. This is evident in the exponential increase in the number of articles appearing in medical journals. ${ }^{23}$ A number of such drugs are available today, including trastuzumab for the treatment of breast cancer and gefitinib for the treatment of lung cancer. ${ }^{26}$ In addition, there is a growing number of pharmaceutical and biotechnology companies that are expanding into this arena, including Roche Pharmaceuticals, Pfizer, GlaxoSmithKline, BristolMyers Squibb/ImClone Systems and Genentech. Currently the industry is worth about $\$ 232$ billion with an anticipated $11 \%$ growth rate per year. ${ }^{27}$ According to Roth, the question is no longer whether to utilize these new pharmacogenomic technologies, but to identify the optimal methods for incorporating them to increase consumer health, while achieving the most advantageous economic benefit. ${ }^{28}$ Even developing countries such as Mexico, Thailand, South Africa and India are entering this market. ${ }^{29}$

The growth of personalized medicine will develop hand-in-hand with the development of companion diagnostic tests. ${ }^{30,31}$ These tests can "identify patients who are not likely to respond to certain treatments based on genetic information" ${ }^{30}$ To date, there are a number of drug manufacturers who have started such development - for instance:

- Amgen has collaborated with Qiagen NV to develop a “companion diagnostic" for Amgen's colorectal oncology drug, Vectibix ${ }^{\circledR}$.

- Pfizer has partnered with Genomic Health, to develop a "prognostic test" to "predict the risk of recurrence in patients with renal carcinoma". This is being developed in collaboration with its new oncology agent, Sutent ${ }^{\circledR}$.

In the next decade, the following developments with regard to personalized medicine are foreseen:

- There will be a huge increase in the number of personalized drugs available - especially in the field of oncology where currently only $5 \%$ of the available drugs are effective in patients. ${ }^{23}$ However, this trend will also extend into other areas of medicine - especially those conditions associated with poor overall drug efficacy. In Jorgensen's opinion, these fields will be oncology, autoimmune diseases and infectious diseases. ${ }^{23}$

- Recently, a rapid, multiplexed genotyping method to identify the single nucleotide polymorphisms (SNPs) that affect warfarin dose has been discovered. ${ }^{32}$ Effectively this converts warfarin into a personalized medicine. It is likely that more and more currently marketed therapies will undergo similar conversions.

- Clinical trial designs will adapt by including "stratification of the study population into biological subgroups... By creating a 'genetically' preselected study population, results should be obtainable in a shorter period of time, and it should also allow for reduction in sample size". ${ }^{31}$ This would ultimately reduce the costs of research and development. In addition, there will be a growing trend to test novel companion diagnostic tests in the same clinical trials. The field of pharmacodiagnostics will mature.

- Pharmacogenetic testing will become more common in the context of clinical trials, and may play a role in drug surveillance (both in the context of clinical trials and postmarketing). For instance, pharmacogenetic testing could be done on individuals who experience severe adverse drug reactions and compared with a control group of patients who did not experience such side-effects.

- Regulatory authorities, such as the FDA and EMEA, will introduce regulations pertaining to the development and marketing of personalized medicine.

- Ethical stances and regulations will emerge with regards to pharmacogenetic testing - especially with regards to the availability for further testing of samples kept in biobanks.

\section{Medical device companies}

In excess of 8000 new medical devices are introduced to the US market per year, with nearly $4 \%$ of all Americans having one or more implanted medical device. ${ }^{33,34}$ In addition, the industry has nearly doubled between 2000 and 2006, making this another important area to focus on for the revitalization of product pipelines. ${ }^{35}$ Current uncertainties regarding the regulatory requirements, $\mathrm{R} \& \mathrm{D}$ costs and reimbursement requirements are causing significant delays in the introduction of many of these devices. ${ }^{36}$

This field is expected to carry on growing in the next decade. Hopefully regulations pertaining to the registration thereof will be resolved. In addition, clinical trials comparing medical devices to standard of care products will also become a reality.

\section{Other trends predicted for the next decade}

- Decreasing rate of adverse drug reactions in clinical practice due to the advancement of nanotechnology and nanomedicine formulation of therapeutics that lead to 
greater therapeutic efficacy with lower drug doses and accompanying lower toxicity. ${ }^{37}$

- The lifestyle drug market (for conditions such as depression, sexual dysfunction, alopecia and obesity) was valued at $\$ 23$ billion in 2008. This market is seen to represent opportunities for pharmaceutical companies seeking new and sustainable revenue streams as traditional markets become increasingly crowded and unprofitable. ${ }^{38}$ Regulations will be developed to protect the consumers of these products.

- Outsourcing of clinical trials is an effective method for pharmaceutical and biotechnology companies to reduce research and developmental costs. Such outsourcing refers not only to the conduct of clinical trials and the manufacturing of medication in developing countries, but also outsourcing to organizations that supply specific services to technology-driven drug discovery partners. ${ }^{39}$ In particular, the clinical research organization business will continue to expand.

- Safety and risk mitigation activities: In the wake of the large number of post-marketing withdrawals in recent years (including Bextra ${ }^{\mathrm{TM}}$, Vioxx ${ }^{\mathrm{TM}}$ and Baycol ${ }^{\mathrm{TM}}$ ), regulatory bodies such as the FDA and EMEA are requiring stringent risk management plans. ${ }^{40,41}$ This practice is likely to evolve further, as is the use of clinical trial registries.

- Fragmentation of the industries, R\&D cost/timelines and empty pipelines will result in further rounds of mergers, acquisitions and licensing agreements for products. ${ }^{6}$ This will hopefully prevent the drainage of company resources by limiting potential financial losses. ${ }^{2}$

- The use of computer modelling and appropriate biomarkers will assist in the discovery of potential new medical entities and thereby aid companies in making more rational and informed decisions with regards to future investments. ${ }^{2,38}$ This will be accompanied by a decline in the use of animal models.

- Companies will take greater advantage of the potential economic benefits afforded by orphan drug development and pediatric research and development.

- There will be an increasing role for, and influence of, NGOs and activist groups at both the national and international level and demand for more transparency and for affordable therapeutics and technology transfer. ${ }^{6}$

\section{Conclusion}

It is more than clear that the current production pipeline for pharmaceutical, biotechnology and medical device industries is no longer sustainable and that urgent interventions are required in order to maintain its current level of profitability. Over the years, however, the pharmaceutical industry has proved itself to be robust and adaptable. No doubt the current challenges and hurdles awaiting it will be dealt with effectively and appropriately. However, it is imperative that such changes be instituted after there is recognition that the environmental threat to current strategy is high, but before the psychological process inherent in coping behavior is engaged. ${ }^{42}$

\section{Disclosure}

The authors report no conflict of interest in this work.

\section{References}

1. BCC Research. World Pharmaceutical Market. Report Code PHM037A. 2004 April. Available from: http://www.bccresearch.com/report/ PHM037A.html. Accessed September 2, 2010.

2. Medical News Today. Pharmaceutical Industry Faces Multiple Challenges - Future lies in Drug Pipeline Sustainability. Medical News Today. 2005, May 26. Available from: http://www.medicalnewstoday. com/printerfriendlynews.php?newsid=25157. Accessed September 26, 2010.

3. Begley S, Carmichael M. Desperately seeking cures. News week. 2010, May 15. Available from: http://www.newsweek.com/id/238078. Accessed September 26, 2010.

4. Fielden MR, Kolaja KL. The role of early in vivo toxicity testing in drug discovery toxicology. Expert Opin Drug Saf. 2008;7(2):107-110.

5. DiMasi JA, Hansen RW, Grabowski HG. The price of innovation: new estimates of drug development costs. J Health Econ. 2003;22(2): 151-185.

6. Bradfield R, El-Sayad ES. Four scenarios for the future of the pharmaceutical industry. Technology Analysis and Strategic Management. 2009;21(2):195-212. Available from: http://dx.doi.org/10.1080/0953 7320802625280. Accessed October 20, 2010.

7. Trombetta W. 2005 Industry audit. Pharmaceutical Executive. 2005 Sptember. Available from: http://www.pharmexec.com/pharmexec/ articleDetail.jsp?id=177964. Accessed October 18, 2010.

8. Kim J. US Generic Drug Industry and Indian Pharmaceutical Companies. 2004, April 26. Available from: http://web.mit.edu/profit/ India $\% 20$ and $\% 20$ Outsourcing $\% 20$ Papers/US $\% 20$ Generics $\% 20$ and\%20Indian\%20Pharma\%20Companies.Final.05.04.doc. Accessed October 18, 2010.

9. Whitehead B, Jackson S, Kempner R. Managing generic competition and patent strategies in the pharmaceutical industry. Journal of Intellectual Property Law and Practice. 2008;3(4):226-235.

10. Department of Economic and Social Affairs. (2002) Chapter 2 Magnitude and Speed of Population Ageing. In: World Population Ageing 1950-2050. Available from: http://www.un.org/esa/population/ publications/worldageing 19502050/pdf/80chapterii.pdf. Accessed October 23, 2010.

11. Centers for Disease Control and Prevention. Chronic disease prevention and health promotion. 2009, December 17. Available from: http:// www.cdc.gov/chronicdisease/resources/publications/aag/aging.htm. Accessed October 25, 2010

12. EFGCP Geriatric Medicines Working Party Workshop. The challenge of an ageing population for medical research: $1 / 3$ of the EU population will be more than 60 years of age in 50 years time. 2009, April 23. Available from: http://www.efgcp.be/Downloads/confDocuments/ Preliminary\%20Progr\%20\%20GMWP\%20Workshop\%20APR\%20 2009\%2009-03-02.pdf. Accessed October 25, 2010.

13. Strein K. Tomorrow's medicine - how to fill a protein pipeline. 2004, November. Available from: http://www.roche.com/pages/downloads/ company/pdf/mb231104ks.pdf. Accessed October 26, 2010. 
14. Thiers FA, Sinskey AJ, Berndt ER. Trends in globalization of clinical trials. Nature Reviews Drug Discovery. 2008;7(1):13-14. Available from: http://dx.doi.org.ezproxy.liv.ac.uk/10.1038/nrd2441. Accessed December 20, 2009.

15. Pharmaceutical-Technology.com [Homepage on the internet]. The Emerging Seven: Pharma's Promised Land. 2009 January. Available from: http://www.pharmaceutical-technology.com/features/ feature48666/. Accessed October 26, 2010.

16. Fillmore D, Thayer AM, Willis RC. Pipeline challenges: major pharmaceutical and biotechnology companies take a variety of approaches Available from: http://pubs.acs.org/subscribe/journals/mdd/v07/i10/ $\mathrm{html} / 1004$ feature_filmore.html. Accessed October 18, 2010.

17. Carlson B. Biologics pipeline set to replenish coffers. Bio Market Trends. 2010:30(14). Available from: http://www.genengnews.com/ gen-articles/biologics-pipeline-set-to-replenish-coffers/3366/. Accessed October 18, 2010.

18. Pfizer. Pfizer Pipeline - Our Medicines in Development. 2010, September 27. Available from: http://www.pfizer.com/research/ pipeline/pipeline.jsp. Accessed October 18, 2010.

19. Novartis. Novartis Products in Development. 2010. Available from: http://www.novartis.com/research/pharmaceutical-product.shtml. Accessed October 18, 2010.

20. Burrill GS. Biotechnology: Past, Present and Future. Bio Pharm International, 1 October 2007. Available from: http://license.icopyright. net/user.viewFreeUse.act?fuid=MTA1MDc3MzA\%3D. Accessed October 26, 2010.

21. Drug Management Forum. Patent expirations for biologics: will there be cost-savings? 2008, February. Available from: http://www.drugman agementforum.com/forum/managed-care-pharmacy-administrativeissues/6504-patent-expirations-biologics-will-there-cost-savings.html. Accessed October 26, 2010

22. Mellstedt $\mathrm{H}$, Niederwieser $\mathrm{D}$, Ludwig $\mathrm{H}$. The challenge of biosimilars.

23. Jorgensen JT, Winther $H$. The new era of personalized medicine: 10 years later. Personalized Medicine. 2009;6(4):423-428. Available from: http:// www.futuremedicine.com/loi/pme. Accessed October 24, 2010.

24. Pirmohamed M, Lewis G. Chapter 16: the implications of pharmacogenetics and pharmacogenomics for drug development and health care. In: Mossialos E, Mrazek M, Walley T, editors. Regulating Pharmaceuticals in Europe: Striving for Efficiency, Equity and Quality. Open University Press, 2004. Available from: http://www.york.ac.uk/res/pgx/publications/pirmohamed\&lewis2004.pdf. Accessed October 24, 2010.

25. Lazarou J, Promeranz BH, Corey PN. Incidence of adverse drug reactions in hospitalized patients: a meta-analysis of prospective studies. JAMA. 1998;279(15):1200-1205.

26. Issa AM. Personalized Medicine and the Practice of Medicine in the 21st Century. Mcgill J Med. 2007;10(1):53-57.

27. Hollis LJ. Experts discuss challenges, promises of personalized medicine. Fierce Bio Tech Research. 2010, March 02. Available from: http://www. fiercebiotechresearch.com/story/experts-discuss-challenges-promisespersonalized-medicine/2010-03-01. Accessed October 23, 2010.

28. Roth M. Personalized medicine: using effective partnering for managing the risk of legal liability. Personalized Medicine, 2007;4(3): 329-339. Available from: http://www.diaceutics.com/Using\%20effective $\% 20$ partnering $\% 20$ for $\% 20$ managing $\% 20$ the $\% 20$ risk $\% 20$ of $\% 20$ legal\%20liability.pdf. Accessed October 24, 2010. to remain productive. Modern Drug Discovery. 2004;7(10):28-33. Ann Oncol. 2008;19(3):411-419.

29. Science News. Personalized Medicine - developing countries show the way. 2008 September 21. Available from: http://www.thenakedscientists. com/HTML/content/news/news/1475/. Accessed October 25, 2010.

30. Bogoslaw D. Personalized Medicine could Shake Up Pharma. Bloomberg Businessweek. 2010 March 02. Available from: http://www. businessweek.com/print/investor/content/mar2010/pi2010032_007178. htm. Accessed October 21, 2010.

31. Jorgensen JT. Are we approaching the post-blockbuster era? Pharmacodiagnostics and rational drug development. Expert Rev Mol Diagn. 2008;8(6):689-695.

32. Science Daily. Personalized Medicine in Warfarin Therapy. 2010 March 7. Available from: http://www.sciencedaily.com/releases/2010/02/ 100225151918.htm. Accessed October 26, 2010.

33. Feigal DW, Gardner SN, McClellan M. Ensuring safe and effective medical devices. $N$ Engl J Med. 2003;348(3):191-192.

34. Feldman MD, Petersen AJ, Karliner LS, Tice JA. Who is responsible for evaluating the safety and effectiveness of medical devices? the role of independent technology assessment. J Gen Intern Med. 2008; 23(Suppl 1): $57-63$.

35. Cheng M. Medical Device Regulations: global overview and guiding principles. World Health Organization, Geneva. 2003. Available from: http://books.google.co.za/books?id=8ECXGuiLgGwC\&printsec $=$ frontcover\&dq=cheng+world+health+organization+medical+devices \&source=bl\&ots=ePMLec $3 \mathrm{WL} 1 \&$ sig $=8 \mathrm{vObWWw0xxmcHR7rdY}$ 4-iHYFHA\&hl=en\&ei=GhyfTLP8NYSWswal5qHmDg\&sa=X\&

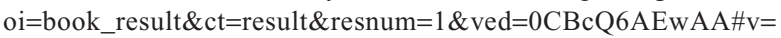
onepage \&q=cheng $\% 20$ world $\% 20$ health $\% 20$ organization $\% 20$ medi cal\%20devices\&f=false. Accessed September 24, 2010.

36. Campbell ND. Replace FDA Regulation of Medical Devices with Third-Party Certification. Cato Policy Analysis No. 288. 1997. Available from: http://www.cato.org/pubs/pas/pa-288.html. Accessed September 26, 2010.

37. Vizirianakis IS. Nanomedicine and personalized medicine toward the application of pharmacotyping in clinical practice to improve drugdelivery outcomes. Nanomedicine. 2011;7(1):11-17.

38. The Lifestyle Drugs Outlook to 2008 in Business Insights, London UK Available from: http://www.marketresearch.com/product/display. asp?productid=933340. Accessed August 13, 2011.

39. Flavin JL. Making the transition from a traditional model to a technology-based drug discovery partner. Contract Pharma, March 2001.

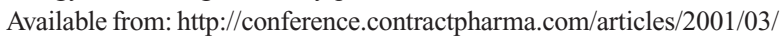
outsourcing-for-the-future. Accessed September 26, 2010.

40. Jamal SM, Eisenberg MJ, Christopoulous S. Rhabdomyolysis associated with hydroxymethylglutaryl-coenzyme A reductase inhibitors. $\mathrm{Am}$ Heart J. 2004;147(6):956-965.

41. US Department of Health and Human Services. (2005) COX-2 Selective (includes Bextra, Celebrex, and Vioxx) and Non-Selective NonSteroidal Anti-inflammatory drugs (NSAIDs). Available from: http:// www.fda.gov/drugs/drugsafety/postmarketdrugsafetyinformationforpatientsandproviders/ucm103420.htm. Accessed October 4, 2010.

42. Wright G, van der Heijden K, Bradfield R, et al. The psychology of why organizations can be slow to adapt and change. Journal of General Management. 2004;29(4):20-35. Available from: http://www.ou.edu/ cls/online/lstd5683b/pdfs/wright.pdf. Accessed August 5, 2011.

Open Access Journal of Clinical Trials

\section{Publish your work in this journal}

The Open Access Journal of Clinical Trials is an international, peerreviewed, open access journal publishing original research, reports, editorials, reviews and commentaries on all aspects of clinical trial design, management, legal, ethical and regulatory issues, case record form design, data collection, quality assurance and data auditing

Submit your manuscript here: http://www.dovepress.com/open-access-journal-of-clinical-trials-journal

\section{Dovepress}

methodologies. The manuscript management system is completely online and includes a very quick and fair peer-review system, which is all easy to use. Visit http://www.dovepress.com/testimonials.php to read real quotes from published authors. 